\title{
An anatomical study of additional radial wrist extensors including a unique extensor carpi radialis accessorius
}

\author{
C.T. West ${ }^{1,2}$, D. Ricketts ${ }^{2}$, C. Brassett ${ }^{1}$ \\ ${ }^{1}$ Human Anatomy Teaching Group, Department of Physiology, Development and Neuroscience, \\ University of Cambridge, United Kingdom \\ ${ }^{2}$ Brighton and Sussex University Hospitals NHS Trust, United Kingdom
}

[Received: 24 March 2017; Accepted: 8 May 2017]

\begin{abstract}
Background: In this study, 82 forearms from 41 cadavers were dissected to establish the incidence of variant additional radial wrist extensors. Three variants have been described in the literature: extensor carpi radialis intermedius (ECRI), extensor carpi radialis accessorius (ECRA) and extensor carpi radialis tertius (ECRT). Materials and methods: Of the 41 cadavers studied, 5/41 (12\%) had an additional radial wrist extensor. Of these 5 individuals, 2 had bilateral additional muscles and 3 were unilateral. Of the 82 forearms, 7/82 (9\%) had additional radial wrist extensors.

Results: We found 4 examples of ECRI and 3 examples of ECRA. We did not find any examples of ECRT. One specimen of ECRA had an atypical, previously undescribed, course.

Conclusions: These accessory muscles are of clinical relevance, as they may be a contributing factor in tennis elbow and nerve entrapment, or cause diagnostic confusion, especially in ultrasound scans. However, they may also be used for tendon transfer. Of the 7 muscles found in the current study, 3 would have been suitable for such procedures. (Folia Morphol 2017; 75, 4: 742-747)
\end{abstract}

Key words: extensor carpi radialis brevis, extensor carpi radialis longus, extensor carpi radialis accessorius, extensor carpi radialis intermedius

\section{INTRODUCTION}

The literature describes two principal extensors at the radial side of the wrist: extensor carpi radialis longus (ECRL) and extensor carpi radialis brevis (ECRB). Three variant additional radial wrist extensors have been described. These are extensor carpi radialis intermedius (ECRI), extensor carpi radialis accessorius (ECRA) and extensor carpi radialis tertius (ECRT).

Additional radial wrist extensors can be clinically relevant in the causation, diagnosis and treatment of upper limb problems. Regarding causation, they may be a contributing factor in nerve entrapment and lateral epicondylitis [11]. Regarding diagnosis, additional wrist extensors have been mistaken for mass lesions [15], split tears of ECRL or ECRB tendons, tendon sheath effusions, synovial cysts or tenosynovial thickening [14]. Regarding treatment, additional extensors have a potential role for tendon transfer in the correction of finger clawing, restoration of finger flexion after flexor muscle loss, and treatment of weakness in thumb opposition $[11,17]$. Two successful cases of ECRI tendon transfer for paralytic disorders of the hand have been described [1]. 
Table 1. Summary of extensor carpi radialis longus (ECRL) and extensor carpi radialis brevis (ECRB)

\begin{tabular}{lcccc}
\hline Muscle & Origin & Muscle belly & Tendinous course & Insertion \\
\hline ECRL & $\begin{array}{c}\text { Distal third of the lateral } \\
\text { supracondylar ridge } \\
\text { of the humerus, lateral } \\
\text { intermuscular septum } \\
\text { and CEO }\end{array}$ & $\begin{array}{c}\text { Extends to junction of the } \\
\text { proximal and middle thirds } \\
\text { of the forearm }\end{array}$ & $\begin{array}{c}\text { Flat tendon along lateral } \\
\text { surface of radius, under APL } \\
\text { and EPB then through the ER } \\
\text { in its second chamber } \\
\text { in a common synovial sheath } \\
\text { posterior to synovial process } \\
\text { of the radius }\end{array}$ & $\begin{array}{c}\text { Radial side of base } \\
\text { of the second } \\
\text { metacarpal }\end{array}$ \\
ECRB & $\begin{array}{c}\text { Deep to ECRL from lateral } \\
\text { intermuscular septum } \\
\text { and CEO }\end{array}$ & $\begin{array}{c}\text { Flat tendon running deep } \\
\text { to the tendon of ECRL }\end{array}$ & $\begin{array}{c}\text { Base of the second } \\
\text { and third metacarpals }\end{array}$ \\
\hline
\end{tabular}

APL — abductor pollicis longus; CEO - common extensor origin; EPB — extensor pollicis brevis; $\mathrm{ER}$ - extensor retinaculum

The anatomy of ECRB and ECRL is summarised in Table 1. These muscles may exchange muscular slips or have tendons that divide into separate slips [3, 4, $9,10]$. The origin of ECRI lies between ECRB and ECRL. The distal tendon runs through the second chamber of the extensor retinaculum (ER) and inserts onto the second or third metacarpal [10]. The incidence of ECRI and its variations are well reported [1, 3, 4, $5,8,17]$. ECRI may have an origin from ECRL or may pass through a separate chamber of the ER [10]. The muscle may also insert more distally, even up to the dorsal digital expansion of the index finger $[2,8,10]$.

In the classic description by Wood (1867) [16], ECRA originates from either the fascia superficial to ECRL and ECRB, or alternatively as a muscular slip from the belly of ECRL itself. Its tendon then goes on to pierce the second chamber of the ER to insert onto the first metacarpal or onto the outer part of abductor pollicis brevis (APB). It may also send a fasciculus to the first dorsal or palmar interosseus [16]. The variations of ECRA are diverse $[3,5,6,12,13,17]$. The tendon may traverse an individual chamber in the ER $[3,5]$. It is also possible for the tendon to cross over the ER superficially [12]. ECRA may insert onto the outer part of APB $[5,7]$, or its tendon may bifurcate to insert onto both the first metacarpal and APB. Alternatively, one part of a bifurcated tendon may travel under the second chamber of the ER and onto the second metacarpal with the other part inserting onto the first metacarpal and APB $[6,12]$.

Nayak et al. (2007) [11] described ECRT, it is similar to ECRI. Its origin is from the common extensor origin (CEO) between ECRL and extensor digitorum. Its tendon divides deep to abductor pollicis longus (APL) to insert onto the base of the second and third metacarpal via the second chamber of the ER.
This study had three aims. Firstly, to determine the incidence of additional radial wrist extensors in a United Kingdom population; secondly, to describe individual variations; and thirdly, to assess the suitability of these additional muscles for use in tendon transfer.

\section{MATERIALS AND METHODS}

The forearms of cadavers used for the anatomical instruction of medical students were examined for the presence of ECRI, ECRA and ECRT. We studied 41 cadavers in total: 19 female and 22 male. When an accessory muscle was found, its tendon was dissected further to determine the data shown in Table 2. All measurements taken were to the nearest $1 \mathrm{~mm}$. Consent had been obtained from all donors for anatomical research prior to bequeathal in accordance with the Human Tissue Act 2004.

\section{RESULTS}

Of the 41 cadavers studied, 5/41 (12\%) had additional radial wrist extensors. Of these 5 individuals, 2 had bilateral additional muscles and 3 were unilateral. Of the 82 forearms examined, 7/82 (9\%) had additional radial wrist extensors.

The muscles found were described and classified by individual donors below. Figures $1-5$ show the additional muscles found for cadavers $A-E$, respectively. The dissection findings are summarised in Table 2.

\section{Cadaver A}

Right forearm. The ECRI had a muscle belly originating from the lateral part of ECRB, giving an independent tendon that ran over the ECRB tendon, underneath APL and extensor pollicis brevis (EPB), and through the second ER tunnel between the 


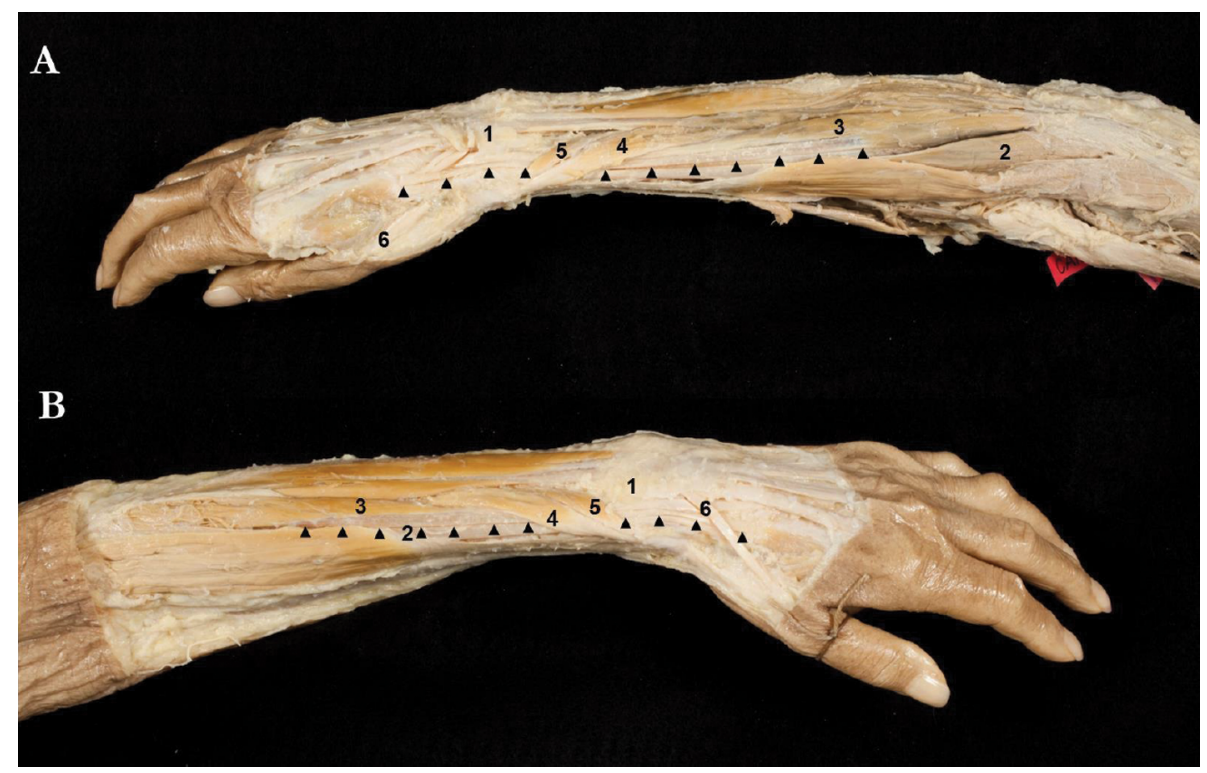

Figure 1. A. Cadaver A; right extensor carpi radialis intermedius; B. Left extensor carpi radialis intermedius; 1 - extensor retinaculum; 2 - extensor carpi radialis longus; 3 - extensor carpi radialis brevis; 4 - abductor pollicis longus; 5 - extensor pollicis brevis; 6 - extensor pollicis longus; additional radial wrist extensors are denoted by black triangles.

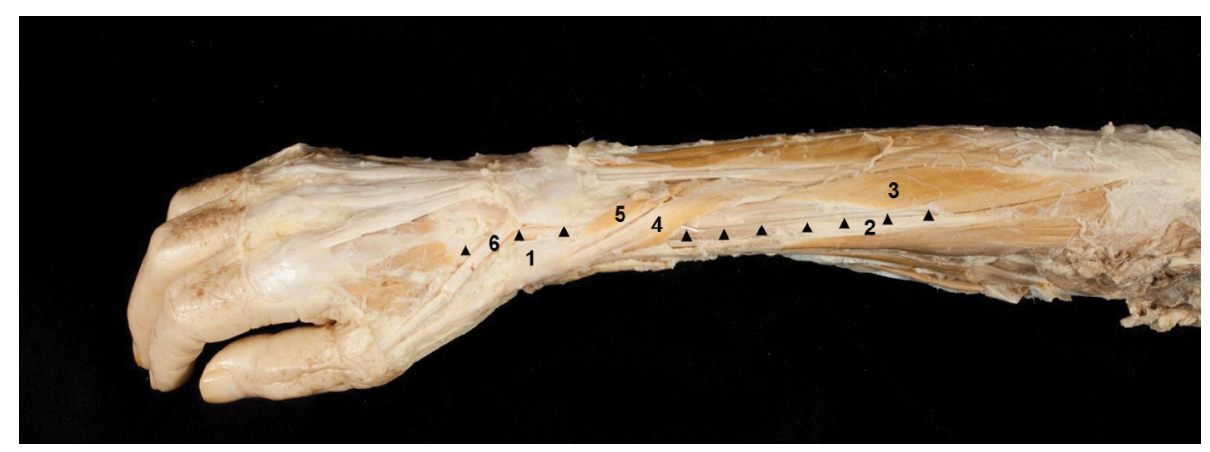

Figure 2. Cadaver B; right extensor carpi radialis intermedius; abbreviations as in Figure 1.

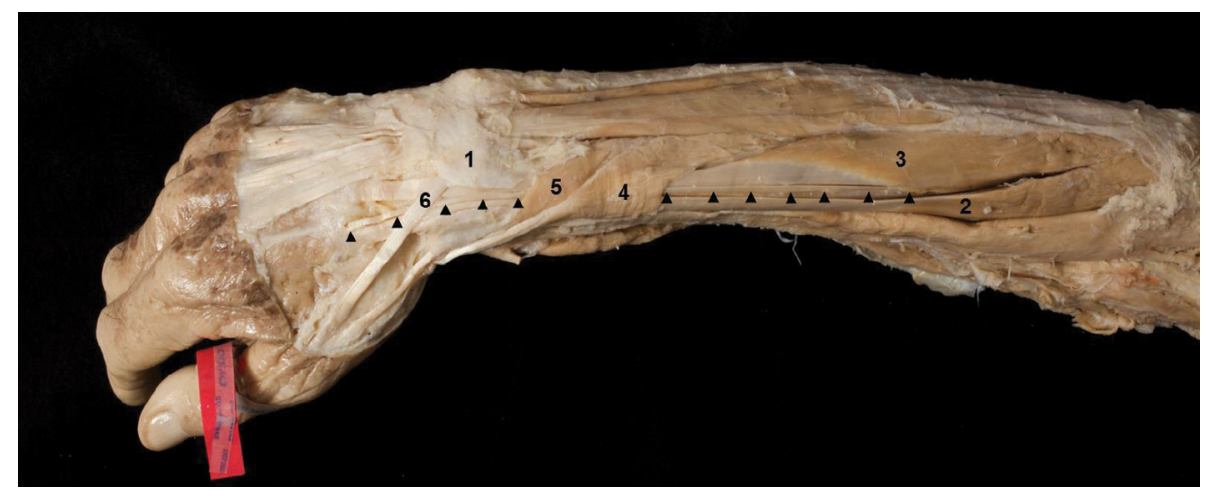

Figure 3. Cadaver C; right extensor carpi radialis intermedius; abbreviations as in Figure 1.

ECRB and ECRL tendons. The insertion lay medial to ECRL and lateral to ECRB on the lateral part of the base of the second metacarpal. The muscle belly was $53 \mathrm{~mm}$ long and maximally $11 \mathrm{~mm}$ wide; the tendon was $184 \mathrm{~mm}$ long and $3 \mathrm{~mm}$ wide at its midpoint. 


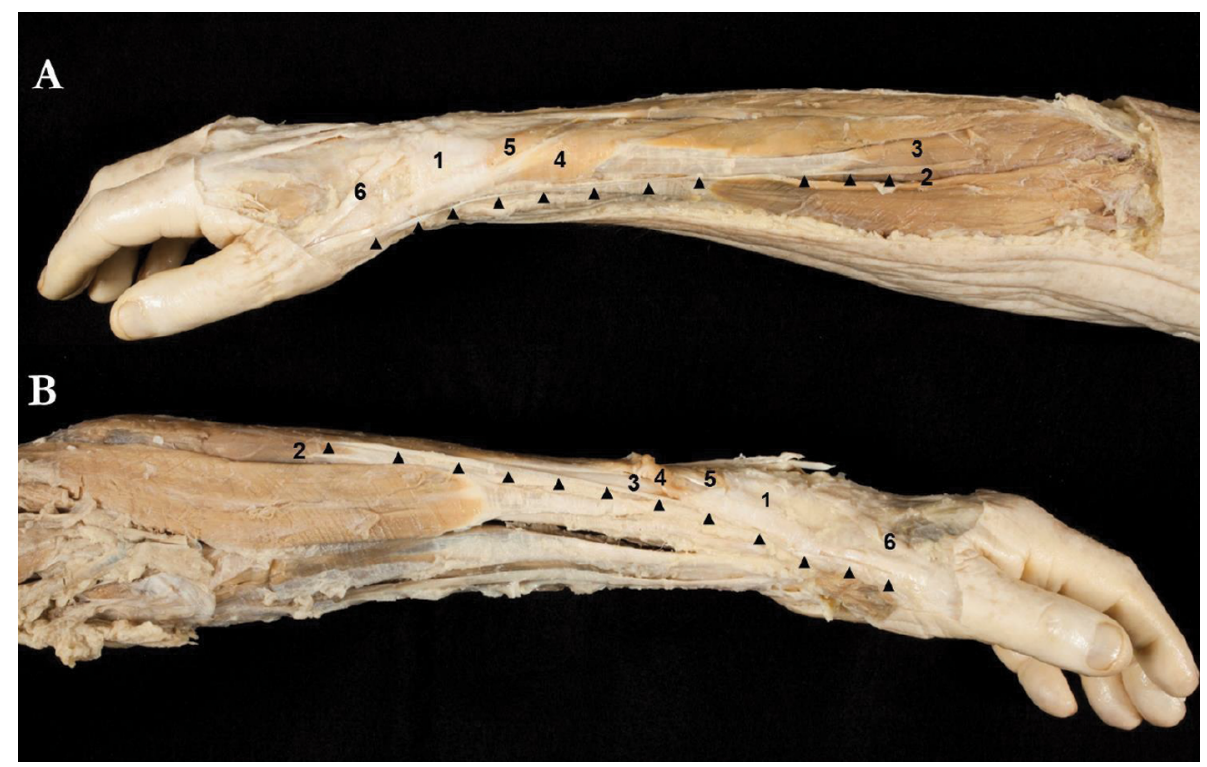

Figure 4. Cadaver D; A. right extensor carpi radialis accessorius; B. Left extensor carpi radialis accessories; abbreviations as in Figure 1.

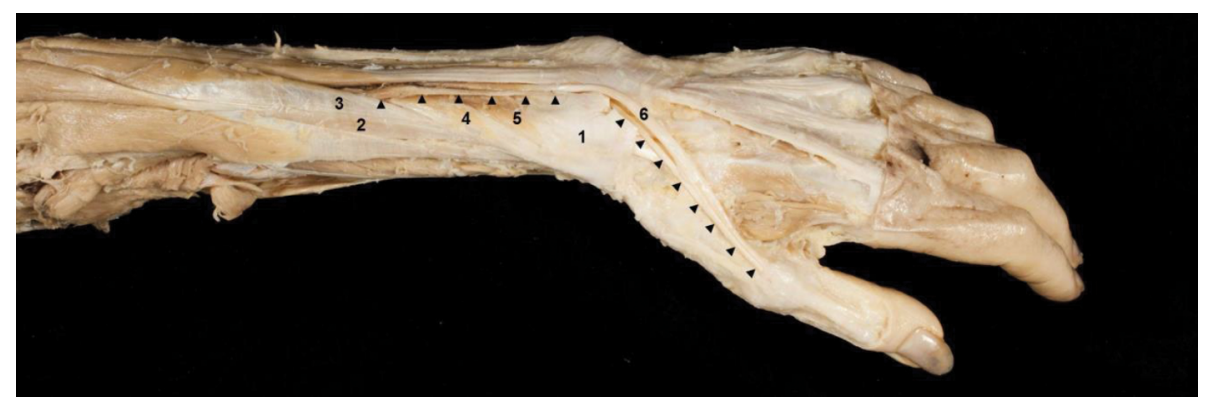

Figure 5. Cadaver E; left extensor carpi radialis accessories; abbreviations as in Figure 1.

Table 2. Summary of dissection findings

\begin{tabular}{|c|c|c|c|c|c|c|c|}
\hline Cadaver & Origin & Tendinous course & Insertion & $\begin{array}{c}\text { Muscle } \\
\text { length [mm] }\end{array}$ & $\begin{array}{l}\text { Maximum } \\
\text { width }[\mathrm{mm}]\end{array}$ & $\begin{array}{c}\text { Tendon } \\
\text { length }[\mathrm{mm}]\end{array}$ & $\begin{array}{l}\text { Tendon width at } \\
\text { midpoint [mm] }\end{array}$ \\
\hline A, Right & $\begin{array}{l}\text { Lateral part } \\
\text { of proximal } \\
\text { ECRB }\end{array}$ & $\begin{array}{c}\text { Over ECRB, under APL and EPB, } \\
\text { through } 2^{\text {nd }} \text { ER tunnel between } \\
\text { ECRB and ECRL }\end{array}$ & $\begin{array}{l}\text { Lateral part } \\
\text { of base of } 2^{\text {nd }} \\
\text { metacarpal }\end{array}$ & 53 & 11 & 184 & 3 \\
\hline A, Left & As for right side & As for right side & As for right side & 83 & 9 & 188 & 3 \\
\hline B, Left & As for $A$ & As for $A$ & As for $A$ & 48 & 7 & 169 & 1 \\
\hline C, Right & As for $A$ & As for $A$ & As for $\mathrm{A}$ & 51 & 6 & 220 & 3 \\
\hline D, Right & $\begin{array}{l}\text { Lateral part of } \\
\text { proximal ECRL }\end{array}$ & $\begin{array}{c}\text { Superficial to brachioradialis, } \\
\text { deep to cephalic vein, through } \\
\text { its' own chamber in ER } \\
\text { posteriorly to APL and APB }\end{array}$ & $\begin{array}{l}\text { Base on } 1^{\text {st }} \\
\text { metacarpal on } \\
\text { the radial side } \\
\text { close to APL }\end{array}$ & 63 & 4 & 191 & 1 \\
\hline D, Left & $\begin{array}{l}\text { As for } \\
\text { right side }\end{array}$ & $\begin{array}{l}\text { As for right side but did } \\
\text { not run over brachioradialis }\end{array}$ & As for right side & 51 & 8 & 198 & 2 \\
\hline E, Left & $\begin{array}{l}\text { From medial } \\
\text { part of ECRB } \\
\text { half way down } \\
\text { muscular part } \\
\text { of its' length }\end{array}$ & $\begin{array}{c}\text { Tendon ran medial to ECRB, } \\
\text { superficial to APL and EPB } \\
\text { to run around Lister's tubercle } \\
\text { lateral to EPB running in same } \\
\text { tunnel of ER as EPL continuing } \\
\text { just lateral to EPL }\end{array}$ & $\begin{array}{c}\text { Dorsal expansion } \\
\text { of the proximal } \\
\text { phalanx } \\
\text { of the thumb }\end{array}$ & 77 & 7 & 109 & 2 \\
\hline
\end{tabular}

APL — abductor pollicis longus; APB — abductor pollicis brevis; ECRB — extensor carpi radialis brevis; ECRL — extensor carpi radialis longus; EPB — extensor pollicis brevis; EPL — extensor pollicis longus; ER — extensor retinaculum 
Left forearm. ECRI was also found in the left forearm with the same origin, course and insertion. Its muscle belly was $83 \mathrm{~mm}$ long and maximally $9 \mathrm{~mm}$ wide; the tendon was $188 \mathrm{~mm}$ long and $3 \mathrm{~mm}$ thick at its midpoint.

\section{Cadaver B}

Right forearm. Unilateral ECRI arising from the right ECRB with its origin, course and insertion as for cadaver A. The muscle belly was $48 \mathrm{~mm}$ long and maximally $7 \mathrm{~mm}$ wide; the tendon was $169 \mathrm{~mm}$ long and $1 \mathrm{~mm}$ wide at its midpoint.

\section{Cadaver C}

Right forearm. Unilateral ECRI with origin, course and insertion as in cadavers A and B. The muscle belly was $51 \mathrm{~mm}$ long and maximally $6 \mathrm{~mm}$ wide; the tendon was $220 \mathrm{~mm}$ long and $3 \mathrm{~mm}$ wide at its midpoint.

\section{Cadaver D}

Right forearm. ECRA with its origin from the lateral part of ECRL. The muscle belly ran partly superficial to brachioradialis deep to the cephalic vein to the ER where it passed through its own channel below that of APL and APB. It then inserted onto the base of the first metacarpal on the radial side near to APL. The muscle belly was $63 \mathrm{~mm}$ long and maximally $4 \mathrm{~mm}$ wide; the tendon was $191 \mathrm{~mm}$ long and $1 \mathrm{~mm}$ wide at its midpoint.

Left forearm. ECRA was also present on the left side with the same origin and insertion as on the right side. The course of the muscle belly was different and did not run superficial to brachioradialis as it did on the left. The muscle belly was $51 \mathrm{~mm}$ long and maximally $8 \mathrm{~mm}$ wide; the tendon was $198 \mathrm{~mm}$ long and $2 \mathrm{~mm}$ wide at its midpoint.

\section{Cadaver E}

Left forearm. Unilateral ECRA with its origin from the medial aspect of the deep surface of ECRB approximately midway along the muscular part of its length. The ECRA tendon ran medial to ECRB, over APL and EPB to wind round the dorsal tubercle of the radius lateral to extensor pollicis longus (EPL). Continuing in the same tunnel of the ER, the tendon continued just lateral to the EPL tendon to the dorsal expansion on the proximal phalanx of the thumb. The muscle belly was $77 \mathrm{~mm}$ and $7 \mathrm{~mm}$ wide; the tendon was $109 \mathrm{~mm}$ long and $2 \mathrm{~mm}$ wide at its midpoint.

\section{DISCUSSION}

The incidence of additional radial wrist extensors

Our study found an additional radial wrist extensor in 5/41 (12\%) of individuals and 7/82 (9\%) of forearms studied. This incidence was similar to previous reports. For individual cadavers an incidence of $19 \%$ has been reported [17]. For forearms, incidences of $10 \%$ [10], 15\% [17] and 24\% [1] have been reported.

\section{Anatomical variation of the muscles found}

ECRI. The four ECRI found in cadavers A-C followed previous descriptions [1, 4, 5, 10, 16, 17].

ECRA. The bilateral ECRAs on cadaver $D$ ran through their own chamber of the ER unlike the classical description, i.e., through the second chamber with ECRB and ECRL, but they did insert onto the first metacarpal [7]. The ECRA of cadaver E (unlike D) arose from the medial side of ECRB and ran through the third chamber of the ER all the way to the dorsal digital expansion of the thumb. This had not been previously described.

ECRT. We did not find an example of ECRT in our study. This may have been due to an inadequate sample number or ethnic variation. The sole previous description of ECRT concerned a cadaver from the Indian subcontinent [11].

\section{Suitability for tendon transfer}

Only 3/7 muscles found in the current study (from cadavers $A$ and $C$ ) would have been sufficiently robust for tendon transfer. Muscle atrophy prior to death may have affected this finding. A previous publication found $32 / 46$ (70\%) of these additional muscles to be suitable for tendon transfer with good excursion, an adequate muscle belly and a strong tendon [17].

\section{CONCLUSIONS}

ECRI or ECRA are present in 10-20\% of forearms based on this study and previous reports. The origin, course and insertion of ECRI were fairly constant as previously described, however those for ECRA varied considerably. If present, additional wrist extensors found could be robust enough for use in tendon transfer.

\section{Acknowledgements}

We acknowledge the kind generosity of our donors and the invaluable assistance of Maria Wright, Darren Broadhurst and Joseph Perfitt in the Human Dissection Room of the University of Cambridge, without whom this study would not have been possible. 


\section{REFERENCES}

1. Albright JA, Linburg RM. Common variations of the radial writs extensors. J Hand Surg Am. 1978; 3(2): 134-138, indexed in Pubmed: 632542.

2. Arora J, Dave V, Kumar A, et al. Unusual architecture of extensor digitorum muscle of hand in conjunction with accessory belly of extensor carpi radialis brevis: a clinicoanatomical insight. Clin Ter. 2013; 164(1): 31-33, indexed in Pubmed: 23455740.

3. Claassen $\mathrm{H}$, Wree $A$. Multiple variations in the region of $\mathrm{Mm}$. extensores carpi radialis longus and brevis. Ann Anat. 2002; 184(5): 489-491, doi: 10.1016/S09409602(02)80084-X, indexed in Pubmed: 12392329.

4. Gümüşalan Y, Kalaycioğlu A, Yazar F, et al. Accessory extensor carpi radialis muscle and interconnecting muscular bundle. Acta Anat (Basel). 1997; 159(1): 57-60, indexed in Pubmed: 9522898.

5. Hong MKY, Hong MKH. An uncommon form of the rare extensor carpi radialis accessorius. Ann Anat. 2005; 187(1): 89-92, doi: 10.1016/j.aanat.2004.08.001, indexed in Pubmed: 15835405.

6. Khaledpour C, Schindelmeiser J. Atypical course of the rare accessory extensor carpi radialis muscle. J Anat. 1994; 184 (Pt 1): 161-163, indexed in Pubmed: 8157488.

7. MacAlister A. Additional observations on muscular anomalies in human anatomy with a catalogue of the principal muscular variations hitherto published (third series). Trans R Ir Acad. 1871; 25: 101-102.

8. Melling $M$, Steindl $M$, Wilde J, et al. An anatomical variant of the extensor carpi radialis brevis muscle. Wien Klin Wochenschr. 2001; 113(23-24): 960-963, indexed in Pubmed: 11802514.

9. Mitsuyasu H, Yoshida R, Shah M, et al. Unusual variant of the extensor carpi radialis brevis muscle: a case report. Clin
Anat. 2004; 17(1): 61-63, doi: 10.1002/ca.10226, indexed in Pubmed: 14695590.

10. Nayak SR, Krishnamurthy A, Prabhu LV, et al. Anatomical variation of radial wrist extensor muscles: a study in cadavers. Clinics (Sao Paulo). 2008; 63(1): 85-90, indexed in Pubmed: 18297212.

11. Nayak SR, Madhan Kumar SJ, Krishnamurthy A, et al. An additional radial wrist extensor and its clinical significance. Ann Anat. 2007; 189(3): 283-286, indexed in Pubmed: 17534036.

12. Olinger A, Benninger B. Unique form of the infrequent extensor carpi radialis accessorius muscle observed bilaterally. Clin Anat. 2010; 23(8): 891-893, doi: 10.1002/ /ca.21003, indexed in Pubmed: 20544794.

13. Roy $S$, Mehta $V$, Suri $R$, et al. Bitendinous insertion of abductor pollicis longus coexistent with a rare accessory antebrachial muscle: clinico-anatomical considerations. Clin Ter. 2010; 161(2): 159-161, indexed in Pubmed: 20499032.

14. Smith J, Pourcho AM, Kakar S. Sonographic appearance of the extensor carpi radialis intermedius tendon. PM R. 2015; 7(7): 789-791, doi: 10.1016/j.pmrj.2015.04.005, indexed in Pubmed: 25857593.

15. Vessal S, Rai SB. Accessory extensor carpi radialis brevis muscle, a pseudomass of the distal forearm: ultrasound and MR appearances -case report and literature review. Clin Radiol. 2006; 61(5): 442-445, doi: 10.1016/j. crad.2005.12.008, indexed in Pubmed: 16679119.

16. Wood J. Variations in human myology observed during the winter session of 1866-67 at King's College, London. Proc R Soc. 1866; 15(0): 518-546, doi: 10.1098/rspl. 1866.0119.

17. Wood VE. The extensor carpi radialis intermedius tendon. J Hand Surg Am. 1988; 13(2): 242-245, indexed in Pubmed: 3351252. 